Illaria Tercelli, MSc ${ }^{1}$ Nuno Ferreira, $\mathrm{PhD}^{2}$

\title{
A systematic review of mindfulness based interventions for children and young people with ADHD and their parents
}

\author{
University of Edinburgh \\ 2University of Nicosia \\ *email: Ferreira.nQunic.ac.cy
}

DOI: $10.2478 / g p-2019-0007$

Received: 26 February 2019; Accepted: 3 March 2019

\begin{abstract}
Objective: Attention deficit hyperactivity disorder (ADHD) is one of the most prevalent disorders in childhood, which may pose risks in later life such as academic underachievement and anti-social behaviour. It has been suggested that mindfulness-based interventions (MBI) may contribute to positive outcomes with child and adult populations. In this article, we aim to systematically review the literature regarding the effectiveness of MBI on both children with ADHD and their parents.

Method: Seven databases were searched using the PRISMA criteria and included peer-reviewed journals and grey literature.

Results: Ten studies met the inclusion criteria. Findings suggested that MBI had positive results in addressing attention deficits in children with ADHD, but in terms of hyperactivity, the evidence was conflicting. MBI interventions also appear to effectively address parental stress and family functioning. However, the rating from the quality assessment showed several methodological limitations.

Discussion: The current evidence on the impact of MBI on ADHD symptoms is non-conclusive. However, promising data indicated the potential for MBI in addressing parental stress and family functioning. Further research is recommended to overcome the current methodological limitations.
\end{abstract}

\section{Keywords}

ADHD, mindfulness, hyperactivity, attention, intervention, systematic review, effectiveness, children, young people, parents.

\section{INTRODUCTION}

Mindfulness entails the self-regulation of attention by increasing the awareness of the here and now and enhancement of nonjudgmental observation (Bishop et al., 2004). Mindfulness is becoming a widespread treatment for individuals with different conditions. A recent randomized control trial (RCT) of a mindfulness based intervention (MBI) has found positive evidence in treating depression, anxiety, stress and adjustment disorders compared to the usual treatment (Sundquist, et al., 2015).

Mindfulness also increases attention due to enhanced selfobservation. For example, Mindfulness-based cognitive therapy (MBCT) emphasizes the importance of metacognitive or executive function (EF) skills and it involves consciously monitoring cognitive processes. Brain imaging studies have demonstrated that mindfulness meditation alters the parts of the brain linked with attention and concentration, which is linked with self-regulation of attention and a substantial reduction in emotionally reactive behaviours (Davidson, 2008; Holtzer et al., 2011). In a study conducted by Kozasa et al. (2012), participants that meditate regularly displayed a better impulse control and attention.

Recent intervention research with children and young people has reflected these positive results. The evidence is growing and it includes studies that have found improvements in attention, executive functioning (EF), emotional reactivity, meta-cognition and behavioural regulation (Flook et al., 2010; Saltzman \& Goldin, 2008; Semple, 2010).

These could be seen as promising results for children with attention deficit hyperactivity disorder (ADHD). At a neurobiological level, children with ADHD display impairments in the prefrontal cortex, which is the area of the brain that regulates the EF and attention (Purper-Ouakil et al., 2011) that is linked to poor performance in EF, including 
self-regulation, response inhibition, working memory and attention.

ADHD entails a significant impact in the quality of life of children. At an academic level, 30\% of children with ADHD underachieve (Kamphaus \& Flick, 1996), have problems developing peer relationships (Wehmeier et al., 2010) and represent $80 \%$ of the total number of pupils permanently excluded per year (O'Regan, 2009). Some children with ADHD may display non-compliant and aggressive behaviour (Pliszka et al., 1999), which may be reflected in 67\% developing oppositional defiant disorder (ODD) and $46 \%$ conduct disorder (CD) (Steinhausen \& Nøvik, 2006). Children with behavioural problems such as ODD and CD might continue displaying antisocial behaviours and other co-morbidities during later stages in life such as: mood disorders, antisocial personality disorders and substance misuse (Cherkasova et al., 2013; Manuzza et al., 1998).

The presence of ODD or CD makes parental stress reach distressing levels (Miranda, et al., 2007). Children are less compliant with their parents' instructions and this creates further situations of conflict. Due to the high stress levels, the parent-child relationship is often compromised. Parents might become less patient, are more aware of disruptive behaviour and become more rejecting and less warm towards the child (Bögels et al., 2010), which in turn lowers the sense of selfconcept among adolescents with ADHD (Putnick et al., 2008). On the other hand, parental stress may cause subsequent burnout and psychiatric problems, including depression and anxiety (Theule et al., 2013). Parental stress is also linked to a higher rate of marital conflict and dissatisfaction, whereas parents tended to blame their children with ADHD for family dysfunctional dynamics (Shelton et al., 1998). According to Kazdin (1995), the implementation of effective psychological strategies with children might be challenging for parents experiencing high levels of stress.

The first-line treatment for children and young people with severe ADHD is pharmacotherapy. Significant therapeutic benefits are experienced in terms of $\mathrm{EF}$ like sustained attention, lower impulsivity, improvements in obedience, collaboration and academic results (Barkley, 2004). Pharmacological treatment has several limitations including: $10 \%$ to $20 \%$ of children are unresponsive to medication (Greenhill et al., 1999); it works short term and there are significant side effects such as decreased appetite and sleep and mood problems (Cascade et al., 2010). Due to these side effects, medication treatment fidelity is low (Domnitei \& Madaan, 2010) and nonadherence reaches $70 \%$ in adolescence (Wolraich et al., 2005).
Moreover, some parents are not inclined to give medication to their children due to their personal values and because of the dubious evidence in neurobiology studies that have attempted to explain the aetiology of ADHD (Acosta et al., 2004; Leo and Cohen, 2003). The theoretical approaches that see ADHD as socially constructed (Timimi \& Taylor, 2003) have gained support and have paved the way to more behavioural and systemic based approaches.

Child behavioural treatment and behavioural parent training (BPT) are the other two most advocated interventions for the treatment of ADHD. Behaviour modification has been evidenced to be an effective intervention for the treatment of ADHD, which can benefit general overall functioning, including decreasing disruptive behaviour, guiding children towards specific goals and improving social skills (Hodgson et al., 2014; Roman, 2010). However, parents are not always coherent in applying the prescribed contingency techniques, and children themselves do not always learn the life-long skills of self-regulation and self-control (Singh et al., 2010). In terms of BPT, a Cochrane review has reported that the evidence is not robust enough in order to develop a foundation for clinical practice guidelines (Zwi et al., 2011). BPT entails rigorous discipline and strategies that might be useful in a short-term but do not teach children self-regulation and might involve coercive dynamics.

The limited success of these programs might also be due to parents being affected by other psychopathologies (van den Hoffdakker et al., 2010) and high level of parental stress and subsequent over-reactivity. However, addressing parental stress is crucial in order to enhance the final outcomes with children exhibiting aggressive and antisocial behaviour (Kazdin et al., 2003). As these interventions address the child-parent conflicting relationship and the core characteristics of the ADHD presentation, other strategies alongside these traditional interventions are needed.

MBIs might be able to address the limitations of the approaches described above. Empirical studies indicate that adding MBI to the contingency management techniques used in behavioural approaches was effective in reducing challenging behaviour displayed in children with autism spectrum disorder (ASD) and stress level in their parents (Singh et al., 2014). Promising results were found in experimental studies where mindfulness based strategies have been implemented with children with ASD and co-morbid ADHD, learning disabilities, and their parents (Benn et al., 2014; Blackledge \& Hayes, 2006; Dykens et al, 2012; Hwang et al., 2015; Singh et al., 2006). In accordance with Singh et al. (2014), these studies have confirmed that 
aggressive behaviour among children and parental stress have decreased due to the use of mindfulness techniques.

Mindful parenting (MP) involves parents incorporating mindfulness techniques in the interactions with their children. MP improved the parent-youth relationship quality, in particular, during the transition to adolescence in a neurotypical population sample (Coatsworth et al., 2009). Bogels et al. (2010) have summarized that MP can address parental stress, dysfunctional parenting schemas and marital conflict regarding child upbringing.

The aforementioned literature suggests that MBI would be able to address the core symptoms of ADHD, including improvements in EF, attentional focus and impulse control; whilst at the same time addressing parental stress and childparent relationship. To the author's knowledge, research that includes the impact of MBI on both children with ADHD and/ or parents has not been previously synthetized in a published systematic review.

The purpose of this systematic review is:

a) to analyse the quality of previous research conducted regarding the effectiveness of $\mathrm{MBI}$ in promoting wellbeing in children with ADHD and their parents

b) specifically to identify whether a relationship exists between MBI and children/adolescents with ADHD in terms of: attention and impulse control demonstrated in reduction in behaviour problems

c) to understand if there is a link between MP and improved relationship with children and subsequent parental stress

d) identify priorities for future research in this area

\section{METHODS}

\section{Inclusion and exclusion criteria}

Journal articles were required to meet the following criteria in order to be included in the present review. These criteria were defined in accordance with the PICO requirements: Population, phenomenon of interest, design, evaluation outcomes and research type (Murdoch University, 2019).

\section{Population}

Participants under 18 years of age with/without their parents. The children met the Diagnostic and Statistical Manual of Mental Disorders (DSM-IV) or the International Classification of Diseases (ICD-10) criteria for ADHD. Studies were excluded if $\mathrm{ADHD}$ was not the primary diagnosis.

\section{Intervention}

The following interventions were included: mindfulness based stress reduction (MBSR; Kabat-Zinn, 1990), mindfulness training for parents (MP; Kabat-Zinn \& Kabat-Zinn, 1997), mindfulness-based cognitive therapy (MBCT; Segal et al., 2002), acceptance and commitment therapy (ACT; Hayes et al., 2004) and mindfulness-based positive behaviour support (MBPBS; Singh et al., 2015). Interventions were delivered by therapists trained in mindfulness based approaches. Studies that used mindfulness only as a component of the intervention (for example, an adjunct to behavioural parent training, BPT) were excluded.

\section{Comparators}

The studies were selected according to the following criteria of eligibility: pre-post quantitative assessment design conducted in any setting, with or without a control group. The studies included in this review were published in English, Italian, French, Spanish and Portuguese in peer-reviewed journals or dissertations.

\section{Outcome measures}

Studies that assessed the effectiveness of outcomes through post-treatment follow-up. The informants of this followup were either the child with ADHD and/or the parent and/ or teacher. Relevant outcomes included behavioural and psychological changes in children with $\mathrm{ADHD}$ and/or parents after MBIs.

\section{Search strategy}

The review assessed existing research and followed the preferred reporting items for systematic reviews and metaanalysis (PRISMA) guidelines for systematic reviews (Moher et al., 2009). Studies were collected searching the following databases: PsychINFO (1806-present), EMBASE (1947present), MEDLINE (1946-present), CINAHL (1937-present), ERIC (1966-present), ASSIA (1987-present) and Social Services Abstracts (1979-present). In order to expand the searches to the grey literature and to prevent publication bias, Proquest Dissertation and Thesis (1743-present) and Cochrane Central were also searched. The last search was completed on $15^{\text {th }}$ September 2017.

The main search keywords were the following: 1) mindfulness OR MBCT OR MBPBS OR MBSR OR acceptance; 2) attention deficit hyperactivity disorder OR ADHD OR attention deficit 


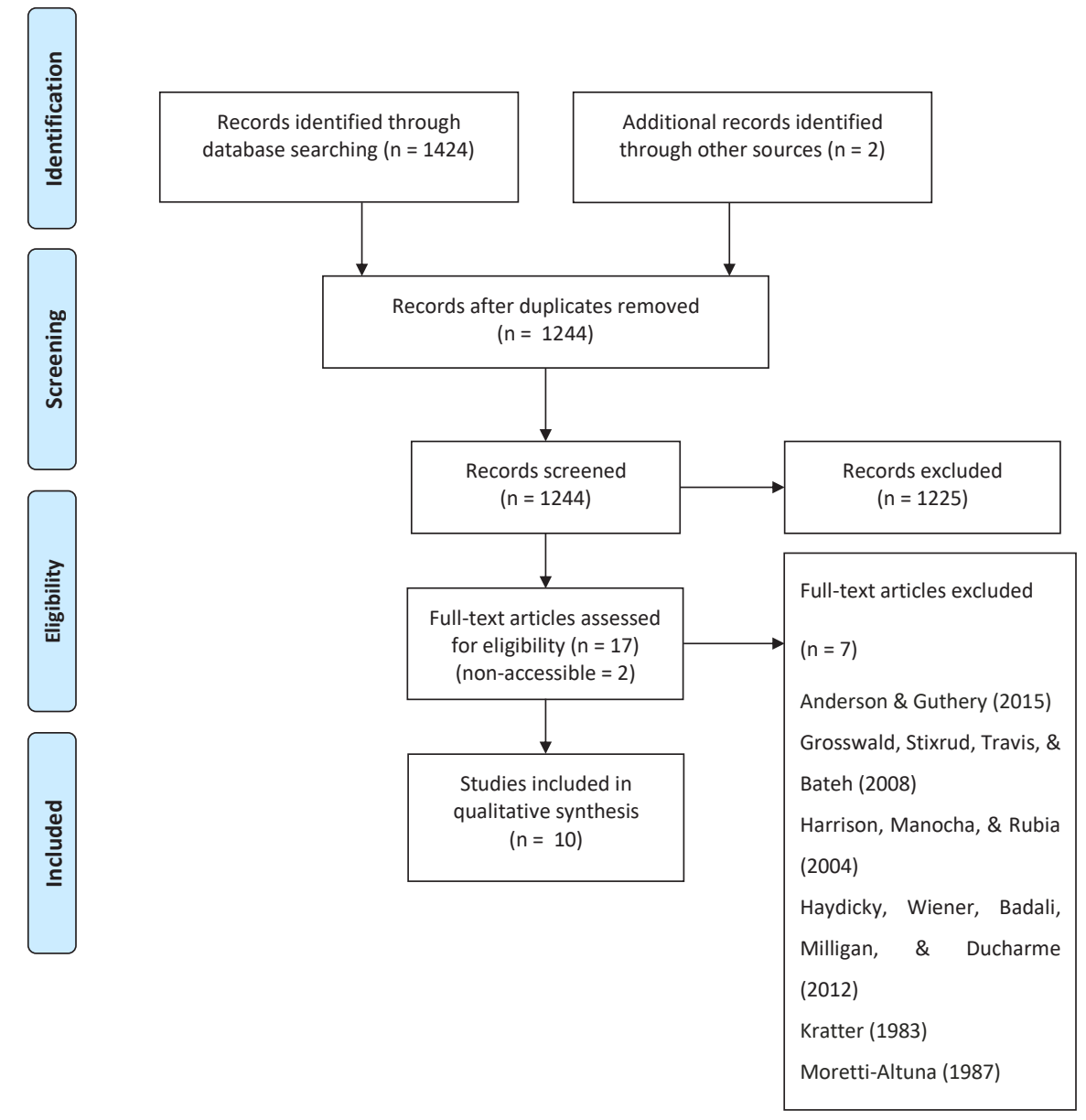

Figure 1. PRISMA Flow Diagram ladapted from Moher et al., 2009)

disorder; 3 ) child ${ }^{\star}$ OR youth OR adolescent ${ }^{\star}$ OR young people, AND/OR parent ${ }^{\star}$ OR mother ${ }^{\star}$ OR father ${ }^{\star}$ OR caregiver ${ }^{\star}$ OR carer*. Following the database searches, Google Scholar was used to find the grey literature. The reference list of articles and dissertations on MBI and ADHD were also closely scrutinized. The process of article selection is illustrated in Figure 1.

\section{Quality appraisal methods}

The quality of the studies included was assessed using a bespoke quality appraisal method tool, 'Quality Indicators for Group Experimental and Quasi-Experimental Research in Special Education' (Gersten et al., 2005). Moreover, elements from the Cochrane EPOC checklist were added to the quality criteria (Greenhalgh, et al., 2005). The criteria provided a comprehensive analysis of the quality of the studies and comprises the following checklist items: research question and design, participants/sampling, treatment fidelity, outcome measures, data analysis, follow-up, attrition and generalizability.
As suggested by Coull and Morris (2011), the first author (I.T.) rated each outcome (research question and design, participants/ sampling, treatment fidelity, outcome measures, data analysis, follow-up, attrition and generalizability ) as: 'well-covered' (2 points); 'adequately addressed' (1 point); and 'poorly addressed', 'not addressed', 'not reported' and 'not applicable' (all 0 points). Each study quality has been then categorized as being: excellent, very good, reasonable and limited. Twenty percent of the articles reached an agreement of $100 \%$ on methodological quality with a second independent rater (N.F.).

\section{RESULTS}

\section{Study selection}

The initial search strategy produced 1424 articles, to which two studies were added from other resources. After the duplicates were removed, a total of 1244 articles remained (the search strategy is elucidated in Figure 1). Through the title screening process, 1225 studies were considered non-eligible to be 
included in the systematic review. The abstract and the full text of 17 studies were carefully examined. Two dissertations were not available in full-text format, so they were excluded.

Upon additional comprehensive reviewing of these articles, 7 studies were excluded from the sample following full-text review, due to: not being an empirically validated mindfulness program but a meditation practice instead (Grosswald et al., 2008; Harrison et al., 2004; Kratter, 1983; Moretti-Altuna, 1987); being a mindful parenting psychoeducation program with no therapist guidance (Anderson \& Guthery, 2015); the primary diagnosis was a learning disability and ADHD was a comorbidity (Haydicky et al., 2012); the results were mixed between children and adults with ADHD (Zylowska, et al., 2008). The final review was based on 10 studies.

\section{Characteristics of included studies}

Ten studies ( see Table 1) were included in this systematic review. Four studies employed a multiple baseline across participants' design (Carboni, 2012; Carboni, et al., 2013; Shecter, 2013; Singh, et al., 2010). Five studies used a quasi-experimental design, and pre- and post-test (Haydicky, et al., 2013; Haydicky, 2014; van de Weijer-Bergsma, et al., 2012; van der Oord, et al., 2012; Worth, 2013). Only one study (Sidhu, 2013) employed a randomized pre-test and post-test with control group design.

This review included studies with a total of 134 children diagnosed with ADHD. In six studies, the children's parents were also receiving mindfulness treatment $(n=89)$. Children were between the age of 8 and 18 years, with the majority of participants being male. According to the data available, the parents were predominantly mothers from a middle-high socio-economic status.

Nine studies reported that some of the participants were on medication for ADHD (range 10-100\%). Four studies reported that children had a comorbid disorder (including: learning disability, depression, anxiety, tic disorder and ODD). In terms of outcome measures, 8 studies utilized well validated tools. Two studies have used measures that were developed by the primary investigator (Shecter, 2013), and single-item rating scales whose psychometric properties were not established (Singh, et al., 2010). Half of the studies were published in peerreviewed journals whilst the remaining were a part of doctoral theses.

\section{Effects of MBI}

Core symptoms of ADHD

\section{Attention - report measures}

Nine studies evaluated whether MBI improved the symptoms of ADHD within a classroom environment and in a home setting through parental/teacher and self-reports, and through computerized tests. The reporting results are consistent in terms of the reduction of inattention. In the only study with a control group design (Sidhu, 2013), it was found that the mindfulness training group showed statistically significant improvements in the attention span as measured in both BASC 2 ( $\eta$ p $2=0.147$, medium effect size) and Conners Parent Rating Scale - Revised ( $\mathrm{p} 2=0.32$, large effect size).

Carboni (2012) and Carboni, et al. (2013) also found an increase in on-task behaviours in classroom setting according to behavioural observations. Where reported, the significant change in attention, reported by parents and teachers, showed a medium to large effect size (Haydicky, et al., 2013; Haydicky, 2014; Sidhu, 2013; van der Oord, et al., 2012; van de Weijer-Bergsma, et al., 2012; Worth, 2013). These results were maintained with a large effect size $(\mathrm{d}=0.80)$ at follow-up in the study by van der Oord et al. (2012).

Some reporting differences were noted among participants. Adolescents did not perceive changes in their inattention level after the MBI in the studies by: Haydicky et al. (2013), Haydicky (2014), and van de Weijen-Bergsma, et al. (2012). Moreover, in the study by van de Weijer-Bergsma, et al. (2012) at the 8-week follow up, the mothers did not report any significant reduction in attention problems, whilst the fathers and adolescents saw a difference with a large effect size $(d=1.5$ and $d=0.9$, respectively). Shecter (2013) noted that 14 parents (64\%) reported that their adolescents experienced less difficulty paying attention after completing the BMI, whilst only four adolescents indicated reductions (44\%).

\section{Attention - computerized measures}

Sidhu (2013) used a Test of Variables of Attention (TOVA) and found that the mindfulness training group showed a significant improvement in inattention as compared to the control group in the infrequent target condition with a medium to large effect size $(\eta p 2=0.21)$. This was also demonstrated in the reaction time and the commission errors tests with a large effect size.

Worth (2013) reported a statistically significant reduction in attentional shifting with a large effect size in both postintervention scores: numbers only $\left(\mathrm{r}^{2}=0.76\right)$ and numbers and letters $\left(r^{2}=0.72\right)$ on the Trail Making Test (TMT). Similar results were found in the Response-Distractor Inhibition Test 
Table 1. Summary overview of included papers

\begin{tabular}{|c|c|c|c|c|}
\hline $\begin{array}{l}\text { Study / Research } \\
\text { Design }\end{array}$ & \begin{tabular}{|l|} 
Sample \\
Characteristics
\end{tabular} & $\begin{array}{l}\text { Treatment, duration and } \\
\text { therapist characteristics }\end{array}$ & $\begin{array}{l}\text { Informant } \\
\text { Measures }\end{array}$ & Treatment key findings \\
\hline $\begin{array}{l}\text { Carboni (2012) } \\
\text { Multiple baseline across } \\
\text { participants' design } \\
\text { (pre-post test design) }\end{array}$ & $\begin{array}{l}\text { Children:4 males } \\
\text { (M age }=8) \\
\text { Medicated: } N=4 \\
(100 \%)\end{array}$ & $\begin{array}{l}\text { - } \text { MBSR } \\
\text { - } 30 \text { to } 45 \text { minutes twice } \\
\text { per week/ } 10 \text { treatment } \\
\text { sessions } \\
\text { - Delivered by school } \\
\text { Psychologist }\end{array}$ & $\begin{array}{l}\text { Teacher and } \\
\text { parent } \\
\text { Measures: } \\
\text { - BASC-2 } \\
\text { - BRIEF } \\
\text { - BOSS }\end{array}$ & $\begin{array}{l}\text { - } \frac{\text { BOSS -On task behavior: increase in the percentage of intervals (between }}{60-62 \%)} \\
\text { - } \frac{\text { BRIEF (teachers): Improvement inhibition (RCI= }-4.29,-5.71) \text {, and Monitor }}{\text { Scale (RCI=-3.40, }-7.95,-7.39)} \\
\text { - BRIEF (parents): Improvement inhibition (RCI=-8.20, }-2.98,-2.98,-7.46) \\
\text { - } \frac{\text { BASC-2 Hyperactive behavior (teachers): decrease in Hyperactivity (RCI= }}{-2.72,-7.27)} \\
\text { - BASC-2 Hyperactive behavior (parents) - decrease in Hyperactivity (RCI= } \\
-3.8,-5.5,-3.05)\end{array}$ \\
\hline $\begin{array}{l}\text { Carboni, } \\
\text { Roach, Friedrick (2013) } \\
\text { Multiple baseline across } \\
\text { participants' design } \\
\text { (pre-post test design) }\end{array}$ & $\begin{array}{l}\text { Children:4 males } \\
\text { (M age }=8 \text { ) } \\
\text { Medicated: } N=4 \\
(100 \%)\end{array}$ & $\begin{array}{ll}\text { - } & \text { MBSR } \\
\text { - } & 30 \text { to } 45 \text { minutes twice } \\
& \text { per week/ at least } 10 \\
& \text { treatment sessions } \\
\text { - } & \text { Delivered by school } \\
& \text { Psychologist } \\
\end{array}$ & $\begin{array}{l}\text { Teacher and } \\
\text { parent } \\
\text { Measures: } \\
\text { - BASC-2 } \\
\text { - BOSS }\end{array}$ & $\begin{array}{l}\text { - } \frac{\text { BOSS - On task behavior: Increase of percentage of intervals }}{\text { BASC-2 Hyperactive behavior (teachers): decrease in Hyperactivity (RCI= }} \\
-2.72,-7.27) \\
\text { - } \frac{\text { BASC-2 Hyperactive behavior (parents): decrease in Hyperactivity (RCl= }}{-3.8,-5.5,-3.05)}\end{array}$ \\
\hline $\begin{array}{l}\text { Haydicky, Shecter, } \\
\text { Wiener \& Ducharme } \\
\text { (2013) } \\
\text { And } \\
\text { Haydicky, (2014) } \\
\text { Quasi-experimental } \\
\text { single group (pre-test, } \\
\text { post-test and follow up) }\end{array}$ & $\begin{array}{l}\text { Children: } \\
5 \text { females and } \\
13 \text { males lage } \\
\text { range 13-18) } \\
\text { Medicated: } N= \\
11(61 \%) \\
\text { Comorbidity: } \\
\text { Learning } \\
\text { disability = } 4 \\
\text { Depressive } \\
\text { disorder }=4 \\
\text { Anxiety disorder } \\
=1 \\
\\
\text { Parents: } \\
17 \text { mothers } 6 \\
\text { fathers }\end{array}$ & $\begin{array}{l}\text { - } \text { MBCT } \\
\text { - } 90 \text { minutes' sessions/ } 8 \\
\text { weeks } \\
\text { - Delivered by Doctoral } \\
\text { students in Clinical } \\
\text { Psychology }\end{array}$ & 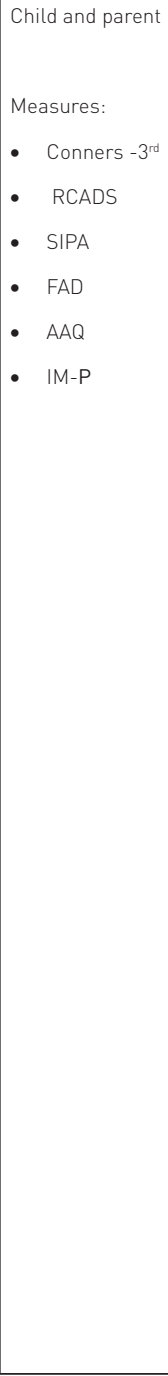 & 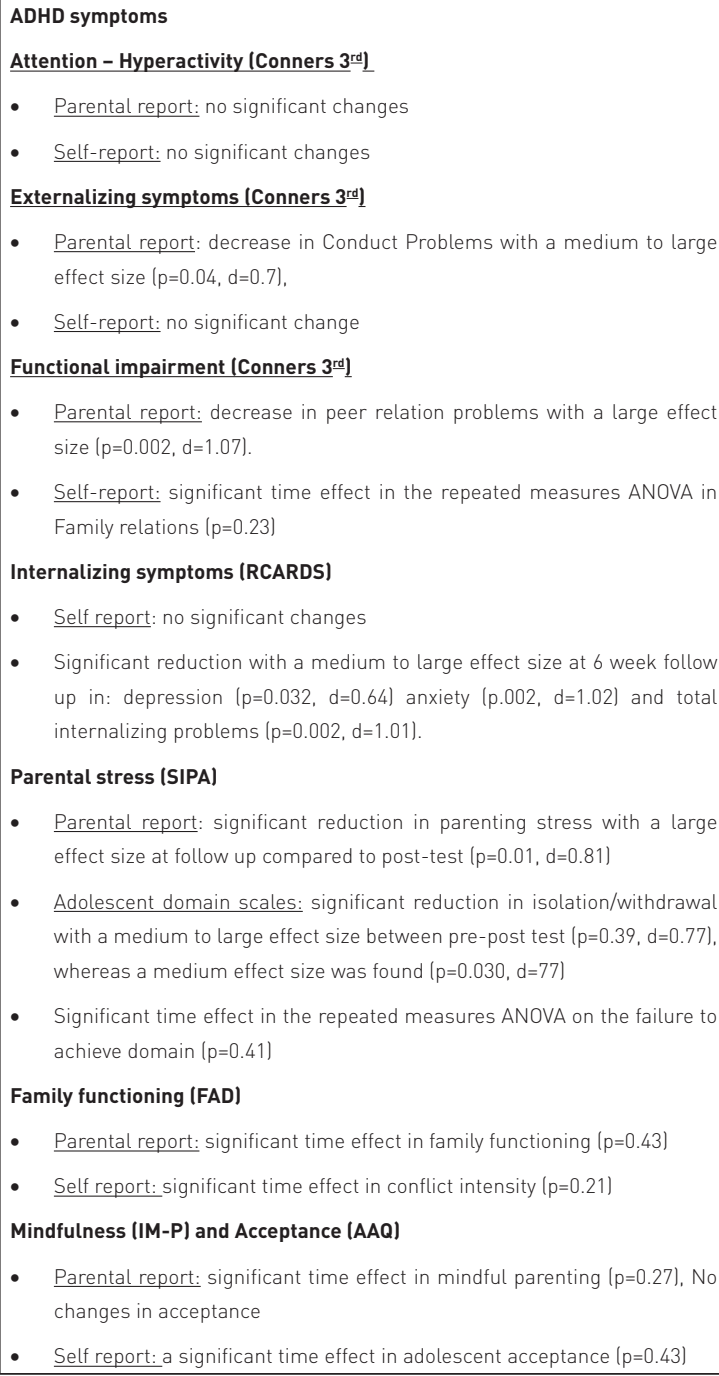 \\
\hline
\end{tabular}


Continued Table 1. Summary overview of included papers

\begin{tabular}{|c|c|c|c|c|}
\hline $\begin{array}{l}\text { Study / Research } \\
\text { Design }\end{array}$ & $\begin{array}{l}\text { Sample } \\
\text { Characteristics }\end{array}$ & $\begin{array}{l}\text { Treatment, duration and } \\
\text { therapist characteristics }\end{array}$ & $\begin{array}{l}\text { Informant } \\
\text { Measures }\end{array}$ & Treatment key findings \\
\hline $\begin{array}{l}\text { Shecter (2013) } \\
\text { Multiple baseline across } \\
\text { participants' design } \\
\text { (pre-post test design) }\end{array}$ & $\begin{array}{l}\text { Children = } 4 \\
\text { females, } 5 \text { males } \\
\text { lage range } \\
13-18 \text { ) } \\
\text { Medicated: } \mathrm{N}=7 \\
\text { Comorbidity: } \\
\text { Learning } \\
\text { disability = 5 } \\
\text { Depression = } 2 \\
\text { Anxiety disorder } \\
=2 \\
\text { Tic Disorder = } 1 \\
\text { Parents: } \\
10 \text { mothers, } 3 \\
\text { fathers }\end{array}$ & $\begin{array}{l}\text { - } \quad \text { MBCT } \\
\text { - } 90 \text { minutes / } 8 \text { weeks } \\
\text { Delivered by Doctoral } \\
\text { students in Clinical } \\
\text { Psychology }\end{array}$ & $\begin{array}{l}\text { Child and parent } \\
\text { Measures: } \\
\text { - } \quad \text { DSQ } \\
\text { - } \quad \text { CSQ }\end{array}$ & 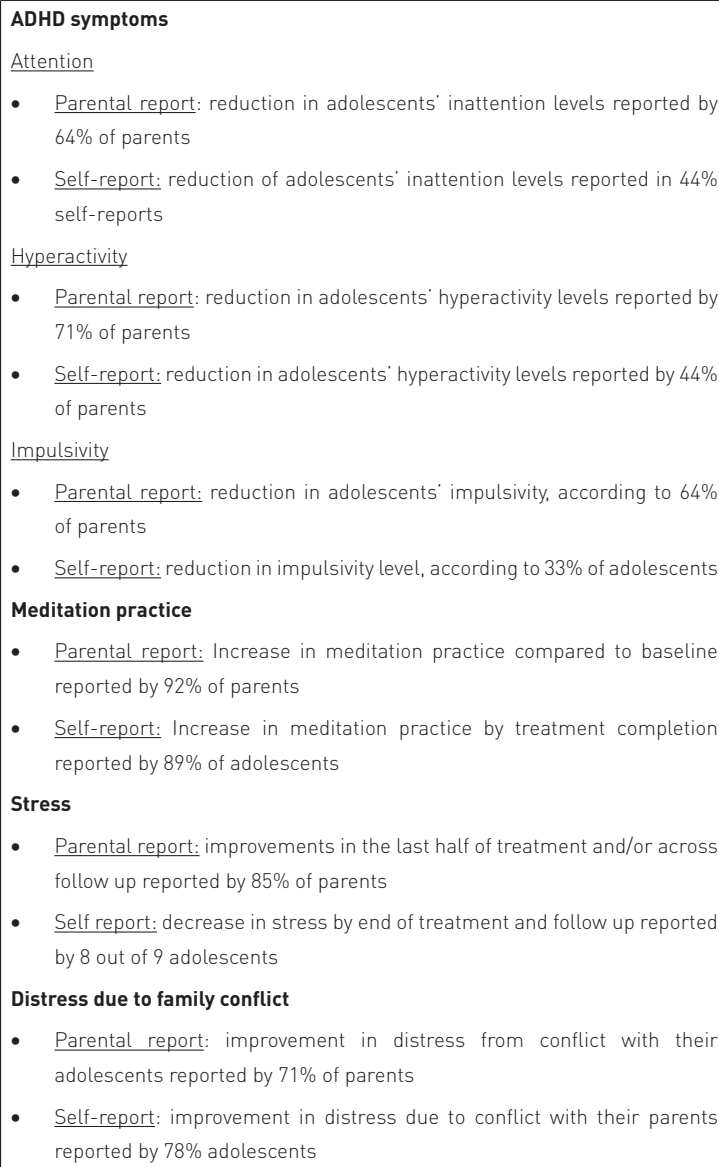 \\
\hline $\begin{array}{l}\text { Sidhu (2013) } \\
\text { Pre-test and post-test } \\
\text { with control group } \\
\text { design }\end{array}$ & $\begin{array}{l}\text { Children: } 34 \\
\text { lage range 7-12) }\end{array}$ & $\begin{array}{ll}\text { - } & \text { SQP } \\
\text { - } & 45 \text { minutes (2 times a } \\
& \text { week for } 4 \text { weeks) }\end{array}$ & $\begin{array}{l}\text { Child and parent } \\
\text { Measures: } \\
\text { - } \quad \text { CPRS-R) } \\
\text { - } \quad \text { BASC - } 2 \\
\text { - } \quad \text { TOVA }\end{array}$ & 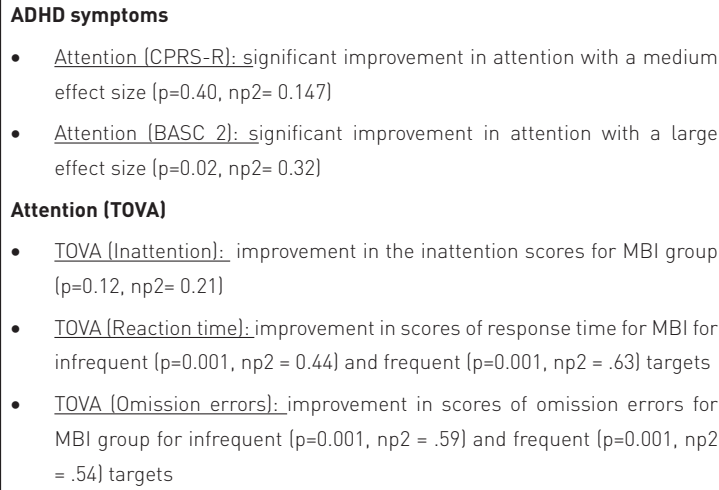 \\
\hline $\begin{array}{l}\text { Singh, Singh, Lancioni, } \\
\text { Singh, Winton \& } \\
\text { Adkins (2010) } \\
\text { Multiple baseline across } \\
\text { participants' design } \\
\text { (pre-post test design) }\end{array}$ & $\begin{array}{l}\text { Children } 2 \text { males } \\
\text { (12 years old) } \\
\text { Medicated: } \mathrm{N}=2 \\
\text { Parents: } 2 \\
\text { mothers }\end{array}$ & $\begin{array}{ll}\text { - } & \text { MBPBS } \\
\text { - } & 12 \text { sessions training for } \\
& \text { each child followed by } \\
& \text { parental training } \\
\text { - } & \text { Delivered by Psychology } \\
& \text { PhD }\end{array}$ & $\begin{array}{l}\text { Child and parent } \\
\text { Measures: } \\
\text { - } \text { SSIMC } \\
\text { - } \quad \text { SUHMC } \\
\text { - Informal } \\
\text { Interviews }\end{array}$ & $\begin{array}{l}\text { Compliance } \\
\text { Mean number of compliant responses after training increased by : } 57.4 \% \\
\text { (Chris) and } 322 \% \text { (Will) } \\
\text { Mother's requests } \\
\text { Mean number of mother's requests after training decreased :by } 31.2 \% \text { (Judy) } \\
12.1 \% \text { (Denise)from parent training to child training, and by } 43.8 \% \text { from child } \\
\text { training to follow up } \\
\text { Child-parent relationship. } \\
\text { Increase in satisfaction among parents regarding the interaction with the } \\
\text { child, further increase in follow up. }\end{array}$ \\
\hline
\end{tabular}


Table 1. Summary overview of included papers

\begin{tabular}{|c|c|c|c|c|}
\hline $\begin{array}{l}\text { Study / Research } \\
\text { Design }\end{array}$ & \begin{tabular}{|l|} 
Sample \\
Characteristics
\end{tabular} & $\begin{array}{l}\text { Treatment, duration and } \\
\text { therapist characteristics }\end{array}$ & \begin{tabular}{|l|} 
Informant \\
Measures
\end{tabular} & Treatment key findings \\
\hline $\begin{array}{l}\text { van de Weijer- } \\
\text { Bergsma, Formsma, de } \\
\text { Bruin \& } \\
\text { Bogels (2012) } \\
\text { Quasi-experimental } \\
\text { (pre-post test design) }\end{array}$ & $\begin{array}{l}\text { Children: } 5 \\
\text { males and } 5 \\
\text { females lage } \\
\text { range } 11-15 \text { ) } \\
\text { Medicated: } N=1 \\
\text { Parents: } 19\end{array}$ & $\begin{array}{l}\text { - } \text { MBCT } \\
\text { - } 1.5 \mathrm{hr} \text { sessions for } 8 \\
\text { weeks } \\
\text { - Delivered by experienced } \\
\text { CBT therapists }\end{array}$ & 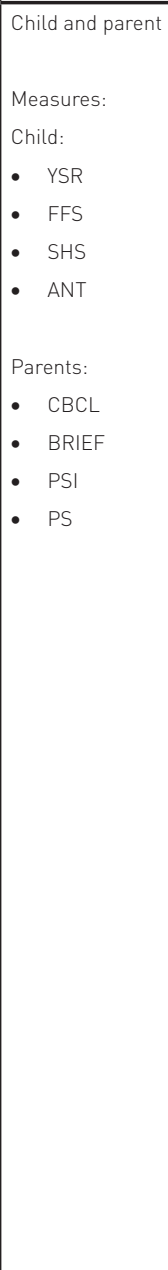 & 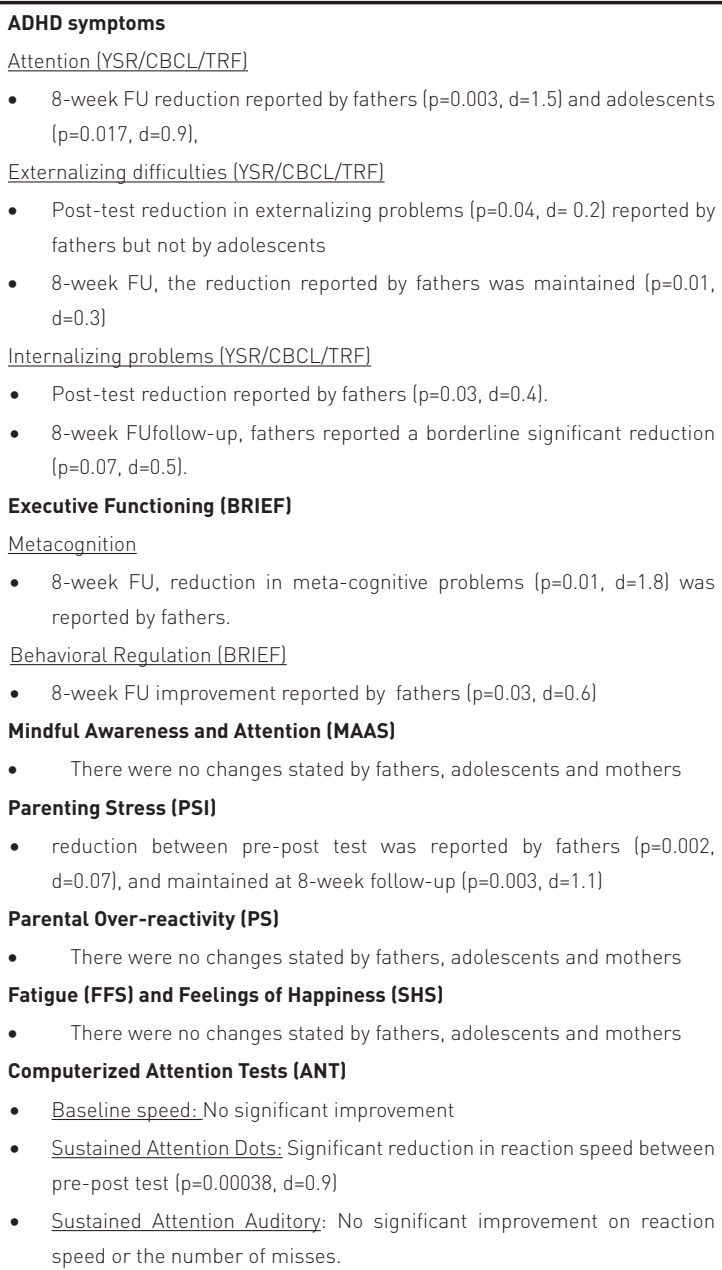 \\
\hline $\begin{array}{l}\text { van der Oord, Bögels, \& } \\
\text { Peijnenburg (2012) } \\
\text { Quasi-experimental } \\
\text { waitlist control (pre- } \\
\text { post-follow up design) }\end{array}$ & $\begin{array}{l}\text { Children: } 13 \\
\text { males and } 5 \\
\text { females lage } \\
\text { range 8-12) } \\
\text { Medicated: } \mathrm{N}=4 \\
\text { Comorbidity: } \\
\text { ODD =3 } \\
\text { Parents: } 21 \\
\text { Mothers }\end{array}$ & $\begin{array}{ll}\text { - } & \text { MBCT and MBSR } \\
\text { - } & 90 \text { minutes sessions/ } 8 \\
& \text { weeks } \\
\text { - } & \text { Delivered by CBT } \\
\text { Therapists }\end{array}$ & $\begin{array}{ll}\text { Teachers and } \\
\text { parent } \\
\text { Measures: } \\
\text { - } \text { DBDRS } \\
\text { - } & \text { ARS } \\
\text { - } & \text { MASS } \\
\text { - } & \text { PSII } \\
\text { - } & \text { PS }\end{array}$ & 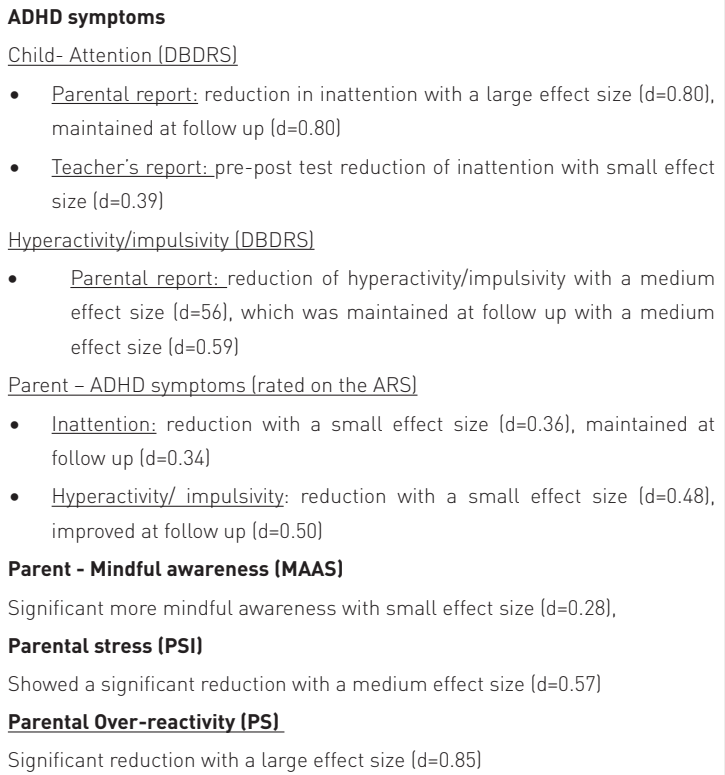 \\
\hline
\end{tabular}


Table 1. Summary overview of included papers

\begin{tabular}{|c|c|c|c|c|}
\hline $\begin{array}{l}\text { Study / Research } \\
\text { Design }\end{array}$ & $\begin{array}{l}\text { Sample } \\
\text { Characteristics }\end{array}$ & $\begin{array}{l}\text { Treatment, duration and } \\
\text { therapist characteristics }\end{array}$ & $\begin{array}{l}\text { Informant } \\
\text { Measures }\end{array}$ & Treatment key findings \\
\hline $\begin{array}{l}\text { Worth (2013) } \\
\text { Feasibility study (pre- } \\
\text { post test design) }\end{array}$ & $\begin{array}{l}\text { Children: } 12 \\
\text { males and } 5 \\
\text { females lage } \\
\text { range 11-15) } \\
\text { Medicated: } \mathrm{N}=12\end{array}$ & $\begin{array}{ll}\text { - } & \text { MAPs } \\
\text { - } & 1 / 2 \text {-hour session each } \\
\text { day / eight weeks } \\
\text { - } & \text { Delivered by a school } \\
\text { counselor }\end{array}$ & $\begin{array}{l}\text { Teachers and } \\
\text { parents } \\
\text { Measures: } \\
\text { - Conners } 3^{\text {rd }} \\
\text { - SCWT } \\
\text { - TMT } \\
\text { - MASS }\end{array}$ & $\begin{array}{l}\text { ADHD symptoms } \\
\text { Attention } \\
\text { Teacher report: decrease between pre-post Inattention score with } \\
\text { large effect size ( } p=0.001, r 2=0.55) \\
\text { Hyperactivity/lmpulsivity: } \\
\text { - No significant changes } \\
\text { ADHD Index } \\
\text { - } \quad \frac{\text { Teacher report: increase from pre to post-test with a small effect size }}{\text { ( } p=0.008, r 2=0.13 \text { ) }} \\
\text { Response-distractor inhibition (SCWT) } \\
\text { - Significant reduction in Color- Word scores with a large effect size } \\
\text { ( } p=0.001, r 2=0.81) \\
\text { Attentional shifting (TMT) } \\
\text { - TMT-A (numbers only): reduction from pre to post-test with a large effect } \\
\text { size ( } p=0.001, r 2=0.76) \\
\text { - TMT-B (numbers and letters): reduction from pre to post-test with a large } \\
\text { effect size ( } p=0.001, r 2=0.72 \text { ) } \\
\text { Mindfulness (MAAS-A) } \\
\text { Increase in mindfulness after training with large effect size ( } p=0.001, r 2=0.76 \text { ) }\end{array}$ \\
\hline
\end{tabular}

Table note: MBSR - Mindfulness Based Stress Reduction (Saltzaman \& Goldin, 2008); MBCT - Mindfulness Based Cognitive Therapy (Borgels et al., 2008); SQP - Still Quiet Place training (Saltzman, 2009); MBPBS - Mindfulness-Based Positive Behavior Supports (Singh et al. 2009); MAPs - Mindful Awareness Practices (Zylowska et al., 2008); BASC - 2 - Behavioural Assessment System for Children; BRIEF Behaviour Rating Inventory of Executive Function; BOSS - Behavioral Observation of Students in Schools; RCADS - Revised Child Anxiety and Depression Scale - Youth and Parent Report; SIPA - Stress Index for Parents of Adolescents; FAD - Family Assessment Device; AAQ - Acceptance and Action Questionnaire; IM-P - Interpersonal Mindfulness in Parenting Scale; DSQ - Daily Symptoms Questionnaire; CSQ - Consumer-Satisfaction Questionnaire; CPRS-R - Conners' Parent Rating Scale - Revised; TOVA - Test of Variables of Attention; SSIMC - Satisfaction with self in interaction with my child; SUHMC - Subjective units of happiness with my child; YSR - Youth Self Report; FFS - Flinders Fatigue Scale; SHS - Subjective Happiness Scale; ANT - Computerized Tests of Attention; CBCL - Child Behaviour Checklist; PSI - Parenting Stress Index; PS - Parenting Scale; DBDRS - Disruptive Behaviour Disorder Rating Scale; ARS - ADHD Rating Scale; MASS - Mindfulness Attention and Awareness Scale; SCWT - Stroop Colour and Word Test; TMT - Trial Making Test;

(SCWT), and in the Color-Word scores a large effect size $\left(\mathrm{r}^{2}=\right.$ $0.81)$ at post-intervention.

Van de Weijer-Bergsma, et al. (2012) have found conflicting results when a computerized attention test for baseline speed (BS) was used, with no improvement in reaction time at 8 and 16-weeks follow-up. However, a significant reduction in reaction speed between pre- and post-test with a large effect size $(d=0.9)$ was detected.

\section{Hyperactivity and impulsivity}

Van der Oord, et al. (2012) have found a reduction in hyperactivity and impulsivity with a medium effect size $(\mathrm{d}=$ 56), which was maintained at follow up $(\mathrm{d}=0.59)$. Carboni
(2012) and Carboni et al. (2013) have found that their BASC-2 teacher and parent ratings have indicated an improvement in the ability to inhibit behaviour and a decrease in hyperactive behaviour.

However, these results are not consistent with other studies where parents did not report significant changes in hyperactivity and impulsivity (Haydicky et al., 2013; Worth, 2013). Also, Shecter (2013) noted that, according to parent reports at follow-up, the MBI had a reductive effect on most of the adolescents' hyperactivity (71\%) and impulsivity (64\%) symptoms. However, only $44 \%$ adolescents reported reduced hyperactivity levels from participating in the MBI. 


\section{Executive functioning}

Three studies have studied the impact of MBI on executive functioning. Haydicky et al. (2013) and Haydicky (2014) showed a significant effect of MBI on learning problems $(\mathrm{p}=0.049)$ and executive function $(\mathrm{p}=0.010)$. Using the BRIEF test, van de Weijer-Bergsma et al. (2012) found a borderline reduction in metacognitive problems at pre- and post-test $(\mathrm{p}=0.08, \mathrm{~d}=1.0)$ and at 8 -week follow up ( $\mathrm{p}=0.01, \mathrm{~d}=1.8)$, as reported by the fathers. Tutors and mothers did not see any significant change.

\section{Externalizing difficulties}

Haydicky et al. (2013) and Haydicky (2014) reported that parents found a significant reduction in conduct problems between preand post-test, with a medium to large effect size $(\mathrm{d}=0.7)$. Van de Weijer-Bergsma et al. (2012) found that at post-test, there was a significant reduction in externalizing problems $(\mathrm{d}=0.2)$ reported by the fathers but not by the adolescents, mothers or tutors. At the 8-week follow-up, the reduction reported by the fathers was maintained $(\mathrm{d}=0.3)$ and the adolescents reported a borderline significant reduction $(\mathrm{d}=0.5)$.

\section{Parental stress and general family functioning}

Six studies analysed the impact of MBI on parental stress and the results were consistently positive. In Haydicky et al. (2013) and Haydicky, (2014) parents reported a significant reduction in parenting stress with a large effect size at follow up compared to post-test $(\mathrm{d}=0.81)$. Moreover, the authors found improvements in family functioning $(\mathrm{p}=0.43)$. Shecter $(2013)$ reported that $85 \%$ parents showed improvements in terms of parental stress in the last half of treatment and/or across follow up.

Van der Oord, et al. (2012) noted a significant reduction in parental stress with a medium effect size $(\mathrm{d}=0.57)$ and overreactivity with a large effect size $(\mathrm{d}=0.85)$. Van de WeijerBergsma et al. (2012) found a significant reduction in parenting stress between pre- and post-test reported by the fathers $(\mathrm{d}=$ $0.07)$, which was maintained at the 8-week follow-up $(\mathrm{d}=1.1)$. There was a borderline significant reduction in the parental over-reactivity reported by the mothers between pre- and posttest $(\mathrm{d}=1.0)$, which was not maintained at the follow-up.

Singh et al. (2010) found an increase in child compliance and in satisfaction among parents regarding the interaction with the child, further increased during follow-up. Moreover, Shecter (2013) reported a positive effect of MBI on $71 \%$ of parents' and $78 \%$ of adolescents' self-reported distress from conflict.

\section{Quality of the studies}

Five studies were rated as reasonable according to a bespoke quality appraisal method tool adapted from the article published by Gersten et al. (2005) and with elements from the Cochrane EPOC checklist (Greenhalgh et al., 2005). The significant methodological limitations were related to: outcome measures, data analysis, completeness of data set and follow-up, and attrition (Table 2).

The sample used for the studies is indeed representative of the population of interest as all the participants have received a diagnosis of ADHD. However, most of the participants have a reported comorbid diagnosis, which might lead to confounding factor. As most of the studies have utilized a small sample, this indicates an important methodological limitation that might hinder the subsequent external validity and generalizability of the results (Shadish, 2002).

Another main methodological limitation is that in 9 studies out of 10 , there is a lack of randomized control group, which might again hinder the external validity of the studies. As discussed, five studies used a quasi-experimental design where the internal validity can be at stake. The groups that have received the MBI and the control groups may not be comparable at baseline. The random assignment may allow the participants to have the same opportunity to be allocated to any of the groups and the observed treatment intervention features would be related to chance rather than to methodical considerations. Quasiexperimental design studies are not always able to establish the causal relationship between the intervention and the observed results, particularly if there are significant confounding variables (Gribbons \& Herman, 1997).

The lack of randomized control group might have affected the four studies that have used a multiple baseline design. These studies might have incurred in experimenter biases, which might have hindered the objectivity of their causal effects. It is not clear in all the studies if an inter-rater agreement of two independent observers has been met (Iversen, 2013). Moreover, due to the very small sample (between 2 and 9 children), the results might not be generalized as some characteristics differ more across individuals.

Most of the studies are uncontrolled with no comparison with other treatments to determine whether the improvements are caused by the MBI. In three studies, just one therapist delivered the intervention and the interpersonal skills might have led to the changes rather than the intervention. The MBI were clearly 
Table 2. Ratings of study quality

\begin{tabular}{|c|c|c|c|c|c|c|c|c|c|}
\hline Study & $\begin{array}{l}\text { Research } \\
\text { question } \\
\text { and design }\end{array}$ & $\begin{array}{l}\text { Participants/ } \\
\text { Sampling }\end{array}$ & Fidelity & \begin{tabular}{|l|} 
Outcome \\
Measures
\end{tabular} & Data analysis & $\begin{array}{l}\text { Times of } \\
\text { measurement } \\
\text { follow-up }\end{array}$ & Attrition & Generalizability & $\begin{array}{l}\text { Quality } \\
\text { category }\end{array}$ \\
\hline $\begin{array}{l}\text { Carboni } \\
(2012)\end{array}$ & \begin{tabular}{|l}
$\begin{array}{l}\text { Well } \\
\text { covered }\end{array}$ \\
\end{tabular} & Well covered & \begin{tabular}{|l} 
Well \\
covered
\end{tabular} & Well covered & \begin{tabular}{|l|} 
Poorly \\
addressed
\end{tabular} & \begin{tabular}{|l} 
Poorly \\
addressed
\end{tabular} & $\begin{array}{l}\text { Not } \\
\text { applicable }\end{array}$ & $\begin{array}{l}\text { Adequately } \\
\text { addressed }\end{array}$ & Reasonable \\
\hline $\begin{array}{l}\text { Carboni, et } \\
\text { al. (2013) }\end{array}$ & \begin{tabular}{|l|} 
Adequately \\
addressed
\end{tabular} & Well covered & \begin{tabular}{|l|}
$\begin{array}{l}\text { Well } \\
\text { covered }\end{array}$ \\
\end{tabular} & Well covered & \begin{tabular}{|l|} 
Poorly \\
addressed
\end{tabular} & \begin{tabular}{|l|} 
Poorly \\
addressed
\end{tabular} & \begin{tabular}{|l} 
Not \\
applicable
\end{tabular} & $\begin{array}{l}\text { Adequately } \\
\text { addressed }\end{array}$ & Reasonable \\
\hline $\begin{array}{l}\text { Haydicky, } \\
\text { et al. (2013) }\end{array}$ & \begin{tabular}{|l|}
$\begin{array}{l}\text { Well } \\
\text { covered }\end{array}$ \\
\end{tabular} & Well covered & \begin{tabular}{|l|}
$\begin{array}{l}\text { Well } \\
\text { covered }\end{array}$ \\
\end{tabular} & Well covered & Well covered & Well covered & \begin{tabular}{|l|}
$\begin{array}{l}\text { Well } \\
\text { covered }\end{array}$ \\
\end{tabular} & $\begin{array}{l}\text { Adequately } \\
\text { addressed }\end{array}$ & Excellent \\
\hline \begin{tabular}{|l|} 
Haydicky, \\
(2014) \\
\end{tabular} & \begin{tabular}{|l|}
$\begin{array}{l}\text { Well } \\
\text { covered }\end{array}$ \\
\end{tabular} & Well covered & \begin{tabular}{|l|}
$\begin{array}{l}\text { Well } \\
\text { covered }\end{array}$ \\
\end{tabular} & Well covered & Well covered & Well covered & $\begin{array}{l}\text { Well } \\
\text { covered }\end{array}$ & $\begin{array}{l}\begin{array}{l}\text { Adequately } \\
\text { addressed }\end{array} \\
\end{array}$ & Excellent \\
\hline $\begin{array}{l}\text { Shecter } \\
\text { (2013) }\end{array}$ & \begin{tabular}{|l}
$\begin{array}{l}\text { Well } \\
\text { covered }\end{array}$ \\
\end{tabular} & Well covered & \begin{tabular}{|l|}
$\begin{array}{l}\text { Well } \\
\text { covered }\end{array}$ \\
\end{tabular} & \begin{tabular}{|l|} 
Poorly \\
addressed
\end{tabular} & \begin{tabular}{|l|} 
Poorly \\
addressed
\end{tabular} & $\begin{array}{l}\text { Adequately } \\
\text { addressed }\end{array}$ & \begin{tabular}{|l|} 
Poorly \\
addressed
\end{tabular} & $\begin{array}{l}\text { Adequately } \\
\text { addressed }\end{array}$ & Reasonable \\
\hline $\begin{array}{l}\text { Sidhu } \\
\text { (2013) }\end{array}$ & $\begin{array}{l}\text { Well } \\
\text { covered }\end{array}$ & Well covered & $\begin{array}{l}\text { Adequately } \\
\text { addressed }\end{array}$ & Well covered & Well covered & \begin{tabular}{|l|} 
Poorly \\
addressed
\end{tabular} & \begin{tabular}{|l|}
$\begin{array}{l}\text { Well } \\
\text { covered }\end{array}$ \\
\end{tabular} & $\begin{array}{l}\text { Adequately } \\
\text { addressed }\end{array}$ & Reasonable \\
\hline $\begin{array}{l}\text { Singh, et } \\
\text { al. (2010) }\end{array}$ & \begin{tabular}{|l|}
$\begin{array}{l}\text { Well } \\
\text { covered }\end{array}$ \\
\end{tabular} & \begin{tabular}{|l|} 
Poorly \\
addressed
\end{tabular} & \begin{tabular}{|l|} 
Poorly \\
addressed
\end{tabular} & \begin{tabular}{|l|} 
Poorly \\
addressed
\end{tabular} & \begin{tabular}{|l|} 
Poorly \\
addressed
\end{tabular} & \begin{tabular}{|l|} 
Poorly \\
addressed
\end{tabular} & \begin{tabular}{|l|} 
Not \\
applicable
\end{tabular} & $\begin{array}{l}\text { Adequately } \\
\text { addressed }\end{array}$ & Limited \\
\hline $\begin{array}{l}\text { van de } \\
\text { Weijer- } \\
\text { Bergsma, } \\
\text { et al. 2012) }\end{array}$ & $\begin{array}{l}\text { Well } \\
\text { covered }\end{array}$ & $\begin{array}{l}\text { Adequately } \\
\text { addressed }\end{array}$ & $\begin{array}{l}\text { Well } \\
\text { covered }\end{array}$ & Well covered & Well covered & Well covered & \begin{tabular}{|l} 
Poorly \\
addressed
\end{tabular} & $\begin{array}{l}\text { Adequately } \\
\text { addressed }\end{array}$ & Very good \\
\hline $\begin{array}{l}\text { van der } \\
\text { Oord, et al. } \\
\text { (2012) } \\
\end{array}$ & $\begin{array}{l}\text { Well } \\
\text { covered }\end{array}$ & Well covered & $\begin{array}{l}\text { Adequately } \\
\text { addressed }\end{array}$ & Well covered & Well covered & Well covered & \begin{tabular}{|l} 
Not \\
addressed
\end{tabular} & Well covered & Very good \\
\hline $\begin{array}{l}\text { Worth } \\
\text { (2013) }\end{array}$ & \begin{tabular}{|l} 
Well \\
covered
\end{tabular} & $\begin{array}{l}\text { Adequately } \\
\text { addressed }\end{array}$ & $\begin{array}{l}\text { Adequately } \\
\text { addressed }\end{array}$ & Well covered & Well covered & Not addressed & $\begin{array}{l}\text { Not } \\
\text { addressed }\end{array}$ & $\begin{array}{l}\text { Adequately } \\
\text { addressed }\end{array}$ & Reasonable \\
\hline
\end{tabular}

described, but in some of the studies, there was no reference to treatment fidelity and compliance.

Another concern regarding the methodological quality is that most of the studies relied on self-report and parental data to evaluate the effectiveness of the intervention. According to Cassady (2001) self-reporting measures might create potential biases including: selective memory, exaggeration and misattribution. Moreover, in the case of children with ADHD this is particularly significant. Boys with ADHD were found to overestimate with positive illusory bias, compared to the teacher related criterion (Hoza, et al., 2002).

Therefore, teachers' reports might be more reliable than self-reports. Performance based and observational measures (Carboni, 2012; Carboni et al., 2013; Sidhu, 2013; van de Weijer-Bergsma et al., 2012; Worth, 2013) are generally deemed more reliable in assessing the treatment effects. Therefore, the conflicting evidence regarding the effectiveness of the core symptoms of ADHD and the promising results regarding parental stress and family functioning might be treated with caution due to the methodological limitations of the studies.

\section{DISCUSSION}

The aim of this systematic review was to assess the effects of MBI on ADHD symptoms, parental stress and family functioning. Important results arose from this review, which may direct suggestions for future research and clinical practice. The results from this review support the hypothesis that MBI reduced parental stress, over-reactivity and increased child compliance and satisfaction among parents regarding the interaction with the child. Therefore, the delivery of MBI with parents of children with ADHD has great potential for improving their wellbeing and the relationship with the child. These results resonate with a recent systematic review conducted by Cachia, et al. (2016) within the neurodevelopmental disorders realm: Autism Spectrum Disorder (ASD). They have found supporting evidence for the effectiveness of MBI with parents of children with ASD, in decreasing their stress levels and improving their wellbeing.

However, the results of this review related to the ADHD symptoms, including attention and hyperactivity/impulsivity were conflicting. Some studies found positive outcomes in both attention and hyperactivity/impulsivity, and others lacked 
consistent reports across informants. This echoes the metaanalytic review conducted by Cairncross and Miller (2016) that assessed both children and adults with ADHD. They reported that the findings for attention and hyperactivity/impulsivity were not significant in terms of the impact of MBI.

\section{Strengths and limitations}

The strengths of the method used in this review is the use of grey literature, which included five doctoral dissertations. According to a Cochrane Database Systematic Review, published trials tend to display a larger treatment effect than grey trials. This poses significant implications for people that write systematic reviews who ought to make sure that they detect grey trials, in order to reduce the risk of introducing bias (Hopewell, et al, 2007). As the studies included in this systematic review were clinically diverse and there was a heterogeneity of measures, it was deemed difficult to conduct a meta-analysis. Genuine differences in effects may have been concealed (Green \& Higgins, 2008). The search criteria included studies published in five languages (English, Italian, French, Spanish and Portuguese); however, after close scrutiny of nine databases, the selected studies were solely in English.

As noted, there were some serious methodological weaknesses in the studies. This implies that the outcomes of the studies should be treated with caution, and that consequently, this review also has several limitations. Due to the subject in question being in its infancy, 10 articles were included in this review. The main pitfall that has been found relates to all the studies having used a small sample. As discussed, this might create problems as the small sample size of the studies may affect their statistical power. This can subsequently influence the probability that a true effect is suggested by a nominally statistically significant finding (Button et al., 2013). Therefore, as the quantitative analysis might not have been adequately powered and due to the lack of randomized control groups, the external validity of the studies might not be reached. These studies used a quasi-experimental and multiple baseline designs, which were critiqued for potentially hindering the objectivity of the causal effects and generalizability of the results.

Due to all the studies being based in Europe and North America with families that were predominantly Caucasian and highly educated, this may also reduce the generalizability of the results to other socio-economic and cultural backgrounds (Sue, 1999). The psychometric properties of the outcome measures of two studies (Shecter, 2013; Singh, et al., 2010) have not been established, which poses questions regarding the accuracy of the results of this evidence.
Another important limitation was that 5 studies have partially relied on self-report measures. These might not be considered as objective measures due to the tendency of adolescents with ADHD to underrate the severity of their symptoms (Hoza, et al., 2002). In most of the studies, the main informants were mothers. Only one study (van de Weijer-Bergsma et al., 2012) relied on paternal and maternal reports. Remarkably, the mothers did not report any significant improvements in any child measure, whilst the fathers reported improvements in every measure. This echoes a meta-analysis where it was found that there was a significant difference between mothers and fathers in reporting both internalizing and externalizing problems in children (Duhig, et al., 2000).

Moreover, according to a study by de Nijs et al. (2004), the between-observer agreement (parents and teachers) on the presence of ADHD symptoms within the same situation at home or school, was low. It was found that one of the causes for informant disagreement on ADHD symptoms was parenting stress (van der Oord, et al., 2006). Therefore, reports regarding the symptomatology of ADHD should be collected by both parents and teachers in home and school environments, respectively, in order to provide a comprehensive picture of the child.

Finally, the quality of the studies was assessed according to a bespoke quality criteria based on the article published by Gersten et al. (2005) and with elements from the Cochrane EPOC checklist (Greenhalgh et al., 2005). In order to enhance the quality and robustness of research findings, the existing evidence ought to address the methodological limitations in terms of: participant sampling, research question and design, fidelity, outcome measures, data analysis, follow-up, attrition and generalizability.

\section{Implications for future research}

One difficulty for future research on MBI would be to isolate the treatment effects on the core symptoms of ADHD. This is because of the high comorbidity rates and the first line treatment for ADHD being pharmacotherapy. It is important to stress that this line of research is young, and stronger evidence is needed before MBI could be recommended as an alternative to the usual treatment for children/adolescents with ADHD and their parents. Future research might benefit from the following recommendations.

Research design: It is recommended the replication of the studies with larger samples more representative of populations from different socio-economic and cultural backgrounds in order to address validity risks. Moreover, it would be beneficial 
to apply a random assignment to test intervention effects, including active control conditions.

Participant and intervention characteristics: It would be beneficial to have a more detailed understanding of the participants' characteristics, particularly in terms of comorbidity and use of medication, which might affect the impact of the MBI. Moreover, in order to have a clear idea of the MBI treatment fidelity, the intervention characteristics should be clearly identified.

Power calculations, varied outcome measures and follow-up: power calculations and pre-post intervention measurements should be delivered. Moreover, most of the evidence assessed in this review relied on data collected by either child/parent or parent/teacher. It would be helpful to integrate multi-informant (including both parents) and multi-method assessments in order to reduce measurement errors. Moreover, the use of validated psychometric measures would be helpful in order to demonstrate a reasonable consistency in results. Moreover, the use of qualitative data might enrich the analysis due to the complexity of the ADHD diagnosis, which the use of solely quantitative data might not capture. It is also recommended for future research to collect follow-up data in order to establish if there are sustained advantages from mindfulness based practices being integrated in lifestyles.

\section{Implications for clinical practice}

This review highlights that, even though the evidence is conflicting, there is still scope for MBI to be considered as an adjunct to evidence based treatments for ADHD. Behavioral Parent Training has been recommended for children with ADHD by the National Institute for Health and Clinical Excellence (2008). Due to the significant evidence that concludes that MBI have been effective in decreasing parental stress, there is a solid basis for recommending mindfulness to be incorporated in parenting programs. By applying some principles of Mindful Parenting within the context of parenting programs, it is hoped that this would increase child compliance. Taking into account the problems that some children encounter in terms of side effects and being unresponsive to medications, MBI offer techniques that can be introduced included in an individual lifestyle. Children with ADHD may consequently learn some elements of the life-long skills of self-regulation and self-control in the home environment.

In conclusion, there is some evidence that MBI may have the potential to improve the core symptoms of $\mathrm{ADHD}$ but research using a more robust methodological criterion is vital before clinical recommendations can be made. However, the evidence on the impact of MBI show positive results in terms of decreasing parental stress and family functioning and could be seen as a potential adjunct to current evidence based treatment.

\section{Conclusion}

$\mathrm{ADHD}$ is one of the most diagnosed disorders among children and it is crucial to find ways to help this vulnerable group and their parents. This systematic review has found some evidence that MBI may have the potential to improve the core symptoms of $\mathrm{ADHD}$, however there are conflicting results in terms of decreasing the hyperactivity levels. Moreover, the existing evidence demonstrated positive results in terms of decreasing parental stress and family functioning. MBI could be seen as a potential adjunct to current evidence based treatments, including becoming a component of parenting programs. In Positive Parenting Programs (including Triple P), one of the main components is for parents to use their self-care skills. MBI could become that extra adjunct that would allow parents to become less over-reactive and stressed with their children with ADHD.

The current research has several methodological considerations that should be tackled before clinical recommendations can be made. These include: research design that would include randomization with a larger sample more representative of populations from different socio-economic and cultural backgrounds; more detailed understanding of the participants' characteristics, particularly in terms of co-morbidity and use of medication; power calculations, varied outcome measures and follow-up.

\section{ACKNOWLEDGEMENTS}

No acknowledgements.

\section{ETHICAL APPROVAL}

As no new data was collected for this study (systematic review), no ethical approval was necessary.

\section{INFORMED CONSENT}

As no new data was collected for this study (systematic review), no informed consent was required.

\section{CONFLICTS OF INTEREST}

The authors declare no conflict of interest in conducting this review. 


\section{FUNDING}

This review did not receive any specific grant from funding agencies in the public, commercial or not-for-profit sectors.

\section{REFERENCES}

Acosta, M.T., Arcos-Burgos, M., \& Muenke, M. (2004). Attention deficit/hyperactivity disorder (ADHD): Complex phenotype, simple genotype? Genetics in Medicine, 6, 1-15.

Anderson, S., \& Guthery, A. (2015). Mindfulness-Based Psychoeducation for Parents of Children With Attention-Deficit/ Hyperactivity Disorder: An Applied Clinical Project. Journal of Child and Adolescent Psychiatric Nursing, 28 (1), 43-49.

Barkley, R.A. (2004). Adolescents with attention deficit/hyperactivity disorder: An overview of empirically based treatments. Journal of Psychiatric Practice, 10, 29-56.

Benn, R., Akiva, T., Arel, S., \& Roeser, R. W. (2012). Mindfulness training effects for parents and educators of children with special needs. Developmental Psychology, 48, 1476-1487.

Bishop, S. R., Lau, M., Shapiro, S., Carlson, L., Anderson, N.D., Carmody, J., Segal, Z. V., Abbey, S., Speca, M., Velting, D., (2004). Mindfulness: A proposed operational definition. Clinical Psychology: Science and Practice, 11 (3), 230-241.

Blackledge, J. T., \& Hayes, S. C. (2006). Using acceptance and commitment training in the support of parents of children diagnosed with autism. Child and Family Behavior Therapy, 28 (1), 1-18.

Bogels, S.M., Lehtonen, A., \& Restifo, K. (2010). Mindful parenting in mental health care. Mindfulness, 1, 107-120.

Button, K.S., Ioannidis, J.P.A., Mokrysz, C., Nosek, B.A., Flint, J., Robinson, E.S.J., \& Munafò, M. R. (2013). Power failure: Why small sample size undermines the reliability of neuroscience. Nature Reviews Neuroscience, 14 (5), 365-376.

Cachia, R., Anderson, L., \& Moore, A. (2016). Mindfulness, Stress and Well-Being in Parents of Children with Autism Spectrum Disorder: A Systematic Review. Journal of Child and Family Studies, 25 (1), 1-14.

Cairncross, M., \& Miller, C. (2016). The Effectiveness of Mindfulness-Based Therapies for ADHD: A Meta-Analytic Review. Journal of Attention Disorders, 1-17.
Carboni, J. (2012). The Impact of Mindfulness Training on Hyperactive Behaviors Demonstrated by Elementary Age Children with a Diagnosis of Attention Deficit Hyperactivity Disorder (Doctoral dissertation). Retrieved from ProQuest Dissertations and Theses.

Carboni, J., Roach, A., \& Fredrick, L. (2013). Impact of Mindfulness Training on the Behavior of Elementary Students With AttentionDeficit/Hyperactive Disorder. Research in Human Development, 10 (3), 234-251.

Cascade, E., Kalali, A., \& Wigal, S. (2010). Real-World Data on: Attention Deficit Hyperactivity Disorder Medication Side Effects. Psychiatry, 7 (4), 13-5.

Cassady, J. C. (2001). Self-Reported GPA and SAT: A Methodological Note. Practical Assessment, Research \& Evaluation, 7 (12). 1-4.

Cherkasova, M., Sulla, E. M., Dalena, K. L., Pondé, M. P., \& Hechtman, L. (2013). Developmental Course of Attention Deficit Hyperactivity Disorder and its Predictors. Journal of the Canadian Academy of Child and Adolescent Psychiatry, 22 (1), 47-54.

Coatsworth, J.D., Duncan, L.G., Greenberg, M.T., \& Nix, R.L. (2010). Changing Parents' Mindfulness, Child Management Skills and Relationship Quality with Their Youth: Results from a Randomized Pilot Intervention Trial. Journal of Child and Family Studies, 19, 203-217.

Coull, G., \& Morris, P. G. (2011). The clinical effectiveness of CBT-based guided self-help interventions for anxiety and depressive disorders: A systematic review. Psychological Medicine, 41 (11), 2239-2252.

Davidson, R., \& Lutz, A. (2008). Buddha's Brain: Neuroplasticity and Meditation [In the Spotlight]. Signal Processing Magazine, IEEE, 25(1), 176-174.

de Nijs, P., Ferdinand, F., Bruin, A., Dekker, R., Duijn, E., \& Verhulst, I. (2004). Attention-deficit/hyperactivity disorder (ADHD): Parents' judgment about school, teachers' judgment about home. European Child \& Adolescent Psychiatry, 13(5), 315-320. 
Domnitei, D., \& Madaan, V. (2010). New and extended-action treatments in the management of ADHD: a critical appraisal of lisdexamfetamine in adults and children. Neuropsychiatric Disease and Treatment, 6, 2010, 273-79.

Duhig, A., Renk, K., Epstein, M., \& Phares, V. (2000). Interparental Agreement on Internalizing, Externalizing, and Total Behavior Problems: A MetaDanalysis. Clinical Psychology: Science and Practice, 7 (4), 435-453.

Dykens, E.M., Fisher, M.H., Taylor, J.L., Lambert, W., Miodrag, N. (2014). Reducing Distress in Mothers of Children With Autism and Other Disabilities: A Randomized Trial. Pediatrics, 134 (2), 54-63.

Flook, L., Smalley, S.L., Kitil, M. J., Galla, B.M., Kaiser-Greenland, S., Locke, J., Ishijima, E., \& Kasari, C. (2010) Effects of Mindful Awareness Practices on Executive Functions in Elementary School Children. Journal of Applied School Psychology, 26 (1), 70-95.

Gersten, R., Fuchs, L. S., Compton, D., Coyne, M., Greenwood, C., \& Innocenti, M. S. (2005). Quality Indicators for Group Experimental and Quasi-Experimental Research in Special Education. Exceptional Children, 71 (2), 149-164.

Green, S., \& Higgins, J. (2008). Cochrane handbook for systematic reviews of interventions (Cochrane book series).

Greenhalgh, T., Robert, G., Bate, P., Macfarlane, F., Kyriakidou, 0. (2005). Diffusion of innovations in health service organisations : A systematic literature review. Malden, MA: Blackwell.

Greenhill, L.L., Halperin, J.M., \& Abikoff, H. (1999). Stimulant medications. Journal of the American Academy of Child and Adolescent Psychiatry, 38, 503-512.

Gribbons, B, \& Herman, J. (1997). True and quasi-experimental designs. Practical Assessment, Research \& Evaluation. 5 (14), 1-4.

Grosswald, S. J., Stixrud, W. R., Travis, F., \& Bateh, M. A. (2008). Use of the transcendental meditation technique to reduce symptoms of attention deficit hyperactivity disorder (ADHD) by reducing stress and anxiety: an exploratory study. Current Issues in Education, 10 (2), 1-16.

Hackett, L, \& Hackett, R. (1993). Parental ideas of normal and deviant child behaviour. A comparison of two ethnic groups. The British Journal of Psychiatry, 162, 353-7.

Haydicky, J., Wiener, J., Badali, P., Milligan, K., \& Ducharme, J.M. (2012). Evaluation of a Mindfulness-based Intervention for Adolescents with Learning Disabilities and Co-occurring ADHD and Anxiety. Mindfulness, 3, 151-164.
Haydicky, J., Shecter, C., Wiener, J., \& Ducharme, J. M. (2013). Evaluation of MBCT for Adolescents with ADHD and Their Parents: Impact on Individual and Family Functioning. Journal of Child and Family Studies, 1-19.

Haydicky, J. (2014). Evaluating a Mindfulness-Based Intervention for Adolescents with ADHD and Their Parents: A Mixed Methods Approach (Doctoral dissertation). Retrieved from ProQuest Dissertations and Theses.

Hayes, S. C., \& Strosahl, K. D. (Eds.). (2004). A practical guide to Acceptance and Commitment Therapy. New York: Springer-Verlag.

Harrison, L. J., Manocha, R., \& Rubia, K. (2004). Sahaja yoga meditation as a family treatment programme for children with attention deficit-hyperactivity disorder. Clinical Child Psychology and Psychiatry, 9 (4), 479-497.

Hodgson, K., Hutchinson, A. D., \& Denson, L. (2014). Nonpharmacological Treatments for ADHD A Meta-Analytic Review. Journal of Attention Disorders, 18 (4), 275-282.

Hölzel, B., Lazar, S., Gard, T., Schuman-Olivier, Z., Vago, D., \& Ott, U. (2011). How Does Mindfulness Meditation Work? Proposing Mechanisms of Action From a Conceptual and Neural Perspective. Perspectives on Psychological Science, 6 (6), 537-559.

Hopewell, S., McDonald, S., Clarke, M.J., \& Egger, M. (2007). Grey literature in meta-analyses of randomized trials of health care interventions. Cochrane Database of Systematic Reviews, Issue 2. Art. No.: MR000010. DOI: 10.1002/14651858.MR000010.pub3.

Hoza, B., Pelham, W., Dobbs, J., Sarno Owens, J., Pillow, D., \& Baker, \& Timothy B. (2002). Do Boys With Attention-Deficit/Hyperactivity Disorder Have Positive Illusory Self-Concepts? Journal of Abnormal Psychology, 111 (2), 268-278.

Hwang, Y., Kearney, P., Klieve, H., Lang, W., \& Roberts, J. (2015). Cultivating Mind: Mindfulness Interventions for Children with Autism Spectrum Disorder and Problem Behaviours, and Their Mothers, Journal of Child and Family Studies, 24 (10), 3093-3106.

Iversen I. H. (2013). Single-Case Research Methods: An Overview. In: Madden G.J., Dube W.V., Hackenberg, T.D., Hanley, G.P., Lattal KA, editors. APA handbook of behavior analysis: Vol 1. Methods and principles (pp. 3-32). Washington, DC: American Psychological Association.

Kabat-Zinn, J. (1990). Full Catastrophe Living: Using the Wisdom of Your Body and Mind to Face Stress, Pain, and Illness. New York, NY: Dell. 
Kabat-Zinn, M., \& Zabat-Zinn, J. (1997). Everyday blessings: The inner world of mindful parenting. New York: Hyperion.

Kamphaus, R. W., \& Frick, P.J. (1996). Clinical assessment of children and adolescent personality and behavior. Needham Heights, MA: Allyn and Bacon.

Kazdin, A. E. (1995). Child, parent and family dysfunction as predictors of outcome in cognitive-behavioral treatment of antisocial children. Behaviour Research and Therapy, 33 (3), $271-$ 281.

Kazdin, A., Whitley, M., \& Peterson, L. (2003). Treatment of Parental Stress to Enhance Therapeutic Change Among Children Referred for Aggressive and Antisocial Behavior. Journal of Consulting and Clinical Psychology, 71 (3), 504-515.

Kozasa, E., Sato, J.R., Lacerda, S.S., Barreiros, M., Radvany, J., Russell, T., Sanches, L.G., Mello, L., \& Amaro, E. (2012). Meditation training increases brain efficiency in an attention task. Neurolmage, 59 (1), 745-749.

Kratter, J. (1983). The use of meditation in the treatment of attention deficit disorder with hyperactivity (Doctoral dissertation). Retrieved from ProQuest Dissertations and Theses.

Leo, J.L., \& Cohen, D. (2003). Broken brains or flawed studies? A critical review of ADHD neuroimaging studies. Journal of Mind and Behavior, 24, 29-56.

Manuzza, S., Klein, R.G., Bessler, A., Malloy, P., \& LaPadula, M. (1998). Adult psychiatric status of hyperactive boys grown up. American Journal of Psychiatry, 155, 493-498.

Miranda, A., Marco, R., \& Grau, D. (2007). Parenting Stress in Families of Children with Attention-Deficit/Hyperactivity Disorder: The Impact of ADHD Subtype and Oppositional Defiant Disorder Comorbidity, in Thomas E. Scruggs, Margo A. Mastropieri (ed.) International Perspectives (Advances in Learning and Behavioral Disabilities, Volume 20) Emerald Group Publishing Limited, pp.139- 162.

Moher, D., Liberati, A., Tetzlaff, J., \& Altman, D. (2009). Preferred reporting items for systematic reviews and meta-analyses: The PRISMA statement. Annals of Internal Medicine, 151(4), 264-9.

Moretti-Altuna, G. (1987). The effects of meditation versus medication in the treatment of attention deficit disorder with hyperactivity (relaxation training, impulsivity, Ritalin). Retrieved from ProQuest Dissertations and Theses.
Murdoch University (2019), Systematic Reviews: Using PICO or PICo [online]. Available at: https://libguides.murdoch.edu.au/ systematic/PICO [Accessed 26 Feb. 2019].

National Institute for Health and Clinical Excellence (NICE). (2008). Attention deficit hyperactivity disorder: Diagnosis and management of ADHD in children, young people and adults. Clinical Guideline 9. UK: National Institute for Health and Clinical Excellence. London: NICE.

O'Regan, F. (2009) Persistent disruptive behaviour and exclusion. $A D H D$ in Practice, 1 (1), 8-11.

Pliszka, S.R., Carlson, C.L., \& Swanson, J.M. (1999). ADHD with comorbid disorders: Clinical assessment and management. New York: Guildford Press.

Purper-Ouakil, D., Ramoz, N., Lepagnol-Bestel, A.M., Gorwood, P., \& Simmoneau, M. (2011). Neurobiology of attention deficit/ hyperactivity disorder. Pediatric Research, 69, 69-76.

Putnick, D.L., Bornstein, M.H., Hendricks, C., Painter, K.M., Suwalsky, J.T.D., Collins, W.A. (2008). Parenting stress, perceived parenting behaviors, and adolescent self-concept in European American families. Journal of Family Psychology, 22, 752-762.

Roman, M.W. (2010). Treatments for childhood ADHD part II: Nonpharmacological and novel treatments. Issues in Mental Health Nursing, 31, 616-618.

Saltzman, A., \& Goldin, P. (2008). Mindfulness based stress reduction for school-age children. In S. C. Hayes \& L. A. Greco (Eds.), Acceptance and mindfulness interventions for children adolescents and families (pp. 139-161). Oakland, CA: Context Press/New Harbinger.

Segal, Z. V., Williams, J. M. G., \& Teasdale, J. D. (2002). Mindfulness-based cognitive therapy for depression: A new approach to preventing relapse. New York: Guilford

Semple, R.J. (2010). Does Mindfulness Meditation Enhance Attention? A Randomized Controlled Trial. Mindfulness, 1, 121130.

Shadish, W. R., Cook, T. D., \& Campbell, D. T. (2002). Experimental and quasi-experimental designs for generalized causal inference. Boston, MA: Houghton Mifflin.

Shecter, C. (2013). Mindfulness Training for Adolescents with ADHD and Their Families: A Time-series Evaluation (Doctoral dissertation). Retrieved from ProQuest Dissertations and Theses. 
Sidhu, P. (2013). The Efficacy of Mindfulness Meditation in Increasing the Attention Span in Children with ADHD (Doctoral dissertation). Retrieved from ProQuest Dissertations and Theses.

Singh, N. N., Lancioni, G. E., Karazsia, B. T., Myers, R. E., Winton, A. S. W., \& Latham, L. L. (2015). Effects of training staff in MBPBS on the use of physical restraints, staff stress and turnover, staff and peer injuries, and cost effectiveness in developmental disabilities. Mindfulness, 6, 926-937.

Singh, N. N., Lancioni, G. E., Singh, A. D., \& Winton, A.S. (2011). Adolescents with Asperger Syndrome Can Use a MindfulnessBased Strategy to Control Their Aggressive Behavior. Research in Autism Spectrum Disorders, 5 (3), 1103-1109.

Singh, N. N., Lancioni, G. E., Winton, A. S., Karazsia, B. T., Myers, R. E., Latham, L. L., \& Singh, J. (2014). Mindfulness-based positive behavior support (MBPBS) for mothers of adolescents with autism spectrum disorder: Effects on adolescents' behaviour and parental stress. Mindfulness, 5, 646-657.

Singh, N. N., Lancioni, G. E., Winton, A. S., Fisher, B. C., Wahler, R. G., Mcaleavey, K., \& Sabaawi, M. (2006). Mindful parenting decreases aggression, noncompliance, and self-injury in children with autism. Journal of Emotional and Behavioral Disorders, 14, 169-177.

Singh, N. N., Singh, A. N., Lancioni, G. E., Singh, J., Winton, A. S., \& Adkins, A. D. (2010). Mindfulness training for parents and their children with ADHD increases the children's compliance. Journal of Child and Family Studies, 19 (2), 157-166.

Steinhausen H.C., \& Nøvik TS. (2006). ADORE Study Group. Coexisting psychiatric problems in ADHD in the ADORE cohort. European Child and Adolescent Psychiatry, 15 (1), i25-i29.

Sue, S. (1999). Science, Ethnicity, and Bias. Where Have We Gone Wrong? American Psychologist, 54 (12), 1070-77.

Sundquist, J., Lilja, Å., Palmér, K., Memon, A.A, Wang, X., Johansson, L.M., \& Sundquist, K. (2015). Mindfulness group therapy in primary care patients with depression, anxiety and stress and adjustment disorders: Randomised controlled trial. The British Journal of Psychiatry, 206(2), 128-35.

Theule, J., Wiener, J., Tannorock, R., \& Jenkins, R. (2013). Parenting stress in families of children with ADHD: A meta-analysis. Journal of Emotional and Behavioral Disorders, 21, 3-17.
Timimi, S., \& Taylor, E. (2004). ADHD is best understood as a cultural construct. The British Journal of Psychiatry, 184 (1), 8-9.

van de Weijer-Bergsma, E., Formsma, A. R., de Bruin, E. I., \& Bögels, S. M. (2012). The effectiveness of mindfulness training on behavioral problems and attentional functioning in adolescents with ADHD. Journal of Child and Family Studies, 21 (5), 775-787.

van den Hoofdakker, B.J., Nauta, M.H., van der Veen-Mulders, L., Sytema, S., Emmelkamp, P.M., Minderaa, R.B., \& Hoekstra, P.J. (2010). Behavioral parent training as an adjunct to routine care in children with attention-deficit/hyperactivity disorder: moderators of treatment response. Journal of Pediatric Psychology, 35 (3), 317-26.

van der Oord, S., Bogels, S. M., \& Peijnenburg, D. (2012). The effectiveness of mindfulness training for children with ADHD and mindful parenting for their parents. Journal of Child and Family Studies, 21 (1), 139-147.

Wehmeier, P.M., Schacht, A., \& Barkley, R. (2010). Social and Emotional Impairment in Children and Adolescents with ADHD and the Impact on Quality of Life. Journal of Adolescent Health, 46 (3), 209-217.

Wolraich, M. L., Wibbelsman, C. J., Brown, T. E., Evans, S. W., Gotlieb, E. M., Knight, Ross, E.C., Shubiner, H.H., Wender, E.H., \& Wilens, E.H. (2005). Attention-deficit/hyperactivity disorder among adolescents: A review of the diagnosis, treatment, and clinical implications. Pediatrics, 115, 1734-1746.

Worth, D. (2013). Mindfulness Meditation and Attention-Deficit/ Hyperactivity Disorder Symptom Reduction in Middle School Students (Doctoral dissertation). Retrieved from ProQuest Dissertations and Theses.

Zylowska, L., Ackerman, D., Yang, M., Futrell, J., Horton, N., Hale, Pataki, S., \& Smalley, S. (2008). Mindfulness meditation training in adults and adolescents with ADHD: A feasibility study. Journal of Attention Disorders, 11 (6), 737-46.

Zwi. M., Jones H., Thorgaard. C., York. A., \& Dennis J.A. Parent training interventions for Attention Deficit Hyperactivity Disorder (ADHD) in children aged 5 to 18 years. Cochrane Database of Systematic Reviews 2011, Issue 12. Art. No.: CD003018. DOI: 10.1002/14651858.CD003018.pub3. 